PAPER

\title{
Pyridostigmine in postpolio syndrome: no decline in fatigue and limited functional improvement
}

\author{
H L D Horemans, F Nollet, A Beelen, G Drost, D F Stegeman, M J Zwarts, J B J Bussmann, \\ $M$ de Visser, G J Lankhorst
}

J Neurol Neurosurg Psychiatry 2003;74:1655-1661

See end of article for authors' affiliations

Correspondence to:

Correspondence to:
Herwin Horemans, Department of

Rehabilitation Medicine,

VU University Medical

Centre, PO Box 7057,

1007 MB Amsterdam,

Netherlands:

h.horemans@vumc.nl

Received 5 December 2002

In revised form

3 April 2003

Accepted 22 April 2003
Objectives: To investigate the effect of pyridostigmine on fatigue, physical performance, and muscle function in subjects with postpoliomyelitis syndrome.

Methods: 67 subjects with increased fatigue and new weakness in one quadriceps muscle showing neuromuscular transmission defects, were included in a randomised, double blind, placebo controlled trial of $60 \mathrm{mg}$ pyridostigmine four times a day for 14 weeks. Primary outcome was fatigue (on the "energy" category of the Nottingham health profile). Secondary outcomes included two minute walking distance and quadriceps strength and jitter. Motor unit size of the quadriceps was studied as a potential effect modifier. The primary data analysis compared the changes from baseline in the outcomes in the last week of treatment between groups.

Results: 31 subjects treated with pyridostigmine and 31 subjects treated with placebo completed the trial. No significant effect of pyridostigmine was found on fatigue. The walking distance improved more in the pyridostigmine group than in the placebo group (by $7.2 \mathrm{~m}(6.0 \%) ; p<0.01)$. Subgroup analysis showed that a significant improvement in walking performance was only found in subjects with normal sized motor units. Quadriceps strength improved more in the pyridostigmine group than in the placebo group (by $6.7 \mathrm{Nm}(7.2 \%) ; p=0.15)$. No effect of pyridostigmine was found on jitter.

Conclusions: Pyridostigmine in the prescribed dose did not reduce fatigue in subjects with postpoliomyelitis syndrome. However, it may have a limited beneficial effect on physical performance, especially in subjects with neuromuscular transmission defects in normal sized motor units.
$\mathrm{S}$ ubjects with postpoliomyelitis syndrome ${ }^{1}$ often complain of fatigue $e^{2-4}$ and a deterioration in functional abilities. ${ }^{5-7}$ These symptoms may, in part, reflect neuromuscular transmission defects. ${ }^{8-11}$

The hypothesis in postpoliomyelitis syndrome is that the enlarged motor units which were formed during the recovery phase lose their ability to maintain all their sprouts, which slowly deteriorate. ${ }^{12}$ This deterioration may be accompanied by increasing neuromuscular transmission defects as a result of progressive dysfunction of acetylcholine synthesis and release. ${ }^{12-14}$ The severity of these transmission defects might increase with increasing motor unit size. ${ }^{15}$ Furthermore, polio patients, especially those with postpoliomyelitis syndrome, are often unable to activate their muscles fully, which may be related to neuromuscular transmission defects. ${ }^{16}$

Pyridostigmine, an anticholinesterase inhibitor, prolongs the effectiveness of acetylcholine. In open studies of pyridostigmine in patients with postpoliomyelitis syndrome, both neuromuscular transmission defects and perceived fatigue decreased. ${ }^{8}{ }^{17} 18$ However, a randomised double blind trial failed to confirm a beneficial effect. ${ }^{19}$ In that study, patients were not selected on the basis of a predefined level of fatigue or on the presence of neuromuscular transmission defects, and the responsiveness of the primary outcome measure, the short form 36 item questionnaire (SF-36), may have been insufficient to detect change. ${ }^{20-22}$ Furthermore, the investigators questioned the adequacy of $180 \mathrm{mg}$ of pyridostigmine a day. ${ }^{19}$

The present placebo controlled double blind trial was undertaken to study the effect of $240 \mathrm{mg}$ pyridostigmine a day in a selected group of subjects with postpoliomyelitis syndrome who had an increased level of fatigue and proven neuromuscular transmission defects in a symptomatic quadriceps muscle-a muscle that is functionally important for locomotion. Our primary aim was to investigate the effect of pyridostigmine on perceived fatigue. Secondary objectives were to investigate the effects on physical performance and muscle function.

\section{METHODS}

Patient selection and baseline assessment

Ambulatory subjects with postpoliomyelitis syndrome were included if they had the following:

- a fatigue score of 10 points or more on the short fatigue questionnaire ${ }^{23}$;

- symptoms of postpoliomyelitis muscle dysfunction ${ }^{24}$ in at least one quadriceps muscle;

- neuromuscular transmission defects (mean jitter $>30 \mu \mathrm{s}$ or more than two jitter values of $>40 \mu \mathrm{s}$ ) in the symptomatic quadriceps muscle on single fibre electromyographic stimulation (S-SFEMG) ${ }^{25} 26$;

- a minimum quadriceps strength of $30 \mathrm{Nm}$;

- age between 18 and 70 years.

Exclusion criteria were significant neurological, orthopaedic, cardiovascular, pulmonary, or endocrine disorders, and anaemia or thyroid dysfunction, both checked by blood tests. The quadriceps with the severest symptoms was investigated.

The duration of symptoms of postpoliomyelitis syndrome, the severity of paresis of the legs, and motor unit size of the

Abbreviations: FSS, fatigue severity scale; $M C D$, mean consecutive latency difference; MF, median frequency; MVA, maximum voluntary activation; MVC, maximum voluntary contraction; $\mathrm{NHP}_{\mathrm{E}}$, "energy" category of the Nottingham health profile; S-SFEMG, single fibre electromyographic stimulation 
lateral vastus were recorded at baseline. The severity of paresis was calculated as a sum score of 16 lower extremity muscle groups, ${ }^{4}$ based on manual muscle testing. ${ }^{27}$ The size of at least 10 motor units was estimated from multichannel surface EMG recordings. ${ }^{28}$ Enlarged mean motor unit size was defined as $>4 \mathrm{mV} \cdot \mathrm{ms}^{28}$

The medical ethics committees of the hospitals involved approved the study. All subjects gave their written informed consent.

\section{Randomisation, blinding, and treatment regimen}

Randomisation of treatment allocation was done in blocks of four. All treatment allocations were concealed for the patients as well as the researchers. The data analyst remained blinded until after the primary outcome analyses.

A dose of $60 \mathrm{mg}$ pyridostigmine four times a day was given for 14 weeks. The dose was gradually increased during the first six days from $4 \times 10 \mathrm{mg}$ to $4 \times 60 \mathrm{mg}$, to reduce the chance of adverse effects. From the fourth day onwards, $0.125 \mathrm{mg}$ atropine was added at each dose to mask the parasympathetic effects of pyridostigmine. The placebo treated subjects also received pyridostigmine during the first three days in the same incremental dose to improve blinding. Subsequently, the pyridostigmine was phased out in two days, and from day 6 onwards placebo pyridostigmine was given. From day 4 onwards this was combined with placebo atropine. Drug treatment was taken 1.5 to 2 hours before each study visit. Compliance was checked by counting the remaining pills.

\section{Study design}

Subjects were measured five times: two baseline visits, with a three week interval to check for learning effects, a visit in the fifth and the 14th week of treatment to evaluate acute and chronic effects, and a visit three weeks after cessation of treatment. For each subject, all visits were scheduled at the same time of day. The drug treatment started two weeks after the second baseline visit (range one to three).

\section{Outcome measures}

Primary outcome was the category "energy" in the Nottingham health profile $\left(\mathrm{NHP}_{\mathrm{E}}\right) \cdot{ }^{29}$ Unweighted sum scores ranged from 0 (no complaints) to 100 (answered yes to all questions).

Secondary outcomes included questionnaires and measurements of physical performance and muscle function.

\section{Questionnaires}

The following questionnaires were used:

- The fatigue severity scale (FSS), with a score ranging from 1 (no effect of fatigue on daily life) to 7 (severe, disabling fatigue).$^{30}$

- The subjective benefit of the treatment, ${ }^{31}$ with two questions: (1) "What, in your opinion, is the effect of the treatment?", with answers ranging from 1 : "very much worse", to 7: "very much improved"; and (2) "Compared to the period before treatment, your fatigue complaints have ...?", with answers ranging from 1 : "greatly increased", to 7: "greatly decreased". A score of 4 indicated no change.

\section{Physical performance}

Physical performance was assessed in the following ways:

- The distance walked in two minutes at comfortable speed, and maximum walking performance-the time needed to walk $75 \mathrm{~m}$ as fast as possible.
- The duration of walking in the daily environment, measured with an ambulatory activity monitor. ${ }^{32}$ The sum of walking activities (that is, continuous walking for at least five seconds) in a 48 hour recording was expressed as the percentage of the total recording time. Walking duration was measured at baseline and in the last week of the drug treatment in 24 consecutively enrolled subjects (10 pyridostigmine, 14 placebo).

\section{Muscle function}

Muscle function was determined as follows:

- Maximum quadriceps strength on a chair dynamometer (Kinetic Communicator, Chattecx Corporation, Chattanooga Tennessee, USA). Subjects undertook three isometric maximum voluntary contractions (MVC) at an optimal knee angle with a two minute rest interval; the greatest contraction was included in the analysis.

- Maximum voluntary activation (MVA) of the quadriceps, determined by interpolated stimulation (DS7A stimulator, Digitimer Limited, Welwyn Garden City, Hertfordshire, England). ${ }^{16}$ Unidirectional square wave pulses of $50 \mu \mathrm{s}$ were used at a voltage of $200 \mathrm{~V}$. The current was chosen such that with a $1 \mathrm{~s}$ stimulation of $30 \mathrm{~Hz}$, at least $25 \%$ of the MVC was reached. The quadriceps was stimulated for $40 \mathrm{~ms}$ at $100 \mathrm{~Hz}$ at peak force during an MVC and five seconds later at rest (control tetanus). MVA was calculated from the increment in force produced by stimulation during the MVC (a) and the force due to control stimulation $(b)$ as $(1-a / b) \times 100$. The highest MVA of three attempts was used for the analysis.

- Muscle fatigability of the lateral vastus, determined with surface EMG during a 30 s sustained isometric contraction at $40 \%$ of the MVC that was obtained at the first baseline visit. ${ }^{33}$ Muscle fatigability was quantified as the difference in the median frequency (MF) between the first five and the last five seconds $\left(\mathrm{MF}_{0-5 \mathrm{~s}}-\mathrm{MF}_{25-30 \mathrm{~s}}\right)$.

- Neuromuscular transmission defects (jitter) of the lateral vastus measured with S-SFEMG. ${ }^{34}$ Measurements were done in the week of the second baseline visit and in the 14th week of the treatment period. The mean consecutive latency difference (MCD) was calculated for 20 different muscle fibres. ${ }^{35}$ Jitter was calculated as the mean MCD of the measured muscle fibres.

\section{Sample size and statistical analysis}

With a power of $90 \%$ and a significance level of $0.05,50$ subjects would be needed to show a one item improvement on the $\mathrm{NHP}_{\mathrm{E}} \cdot{ }^{4}$ Taking potential dropout into account, the sample size was set at 64 . The primary analysis compared the subjects receiving pyridostigmine and the subjects receiving placebo with regard to changes in the outcome measures in the 14th week of treatment from the values obtained at the second baseline visit ( $t$ tests). The secondary analysis compared changes from baseline in the outcomes in the fifth week of treatment and three weeks after cessation of treatment between groups. The minimum clinical relevant improvement in the secondary outcome measures was set at $10 \%$. The analyses were based on an intention to treat approach. Subgroup analyses were done for motor unit size (enlarged and normal), and for walking distance and quadriceps strength, for which subgroups were formed on the basis of the median baseline value. All tests were two sided, and statistical significance was set at $\mathrm{p}<0.05$. 


\section{RESULTS}

Sixty seven of the 101 subjects who were screened were included (fig 1). The two groups were comparable with respect to demographic and baseline characteristics (table 1).

Two subjects were excluded after treatment allocation because of thyroid dysfunction and anaemia. Two subjects withdrew from the study, one (pyridostigmine) after four weeks of treatment because of personal circumstances, and one (placebo) after six weeks of treatment because of dissatisfaction with the procedures. In general, the treatment was well tolerated. One subject (pyridostigmine) discontinued the drug because of severe diarrhoea, and was lost to follow up for personal reasons.

\section{Compliance and blinding}

Compliance was good. Fifty five of the 62 subjects who completed the study took at least $90 \%$ of their drug dose. Only two subjects (placebo) took less than $80 \%$ of their dose.

The blinding code was not broken during the trial, and the blinding was successful- $68 \%$ of the subjects receiving pyridostigmine and $47 \%$ of the subjects receiving placebo guessed their actual treatment correctly $(p=0.37)$. The investigator guessed correctly for $39 \%$ of the pyridostigmine treated subjects and for $42 \%$ of the placebo treated subjects $(\mathrm{p}=0.20)$.

\section{Outcome}

There was no significant difference in change on the primary outcome $\mathrm{NHP}_{\mathrm{E}}$ between the two groups during the treatment period (table 2). In the 14th week of treatment, a significant reduction of $36 \%$ was found in both groups. No difference in change on the FSS or in the subjective benefit of the treatment was found between the two groups; both improved significantly during the treatment period.

In the 14th week of treatment, the walking distance improved more in the pyridostigmine group than in the placebo group (by $7.2 \mathrm{~m}(6.0 \%) ; p=0.003)$. No effect of pyridostigmine was found on maximum walking performance. Three weeks after the treatment period the pyridostigmine group improved significantly more than the placebo group on walking distance and maximum walking performance. No difference in change in the duration of walking was found between the two groups. Walking duration increased significantly in the pyridostigmine group.

There was no difference in change in quadriceps strength between the two groups. In the 14th week of treatment, significant improvements were found in both groups. In the

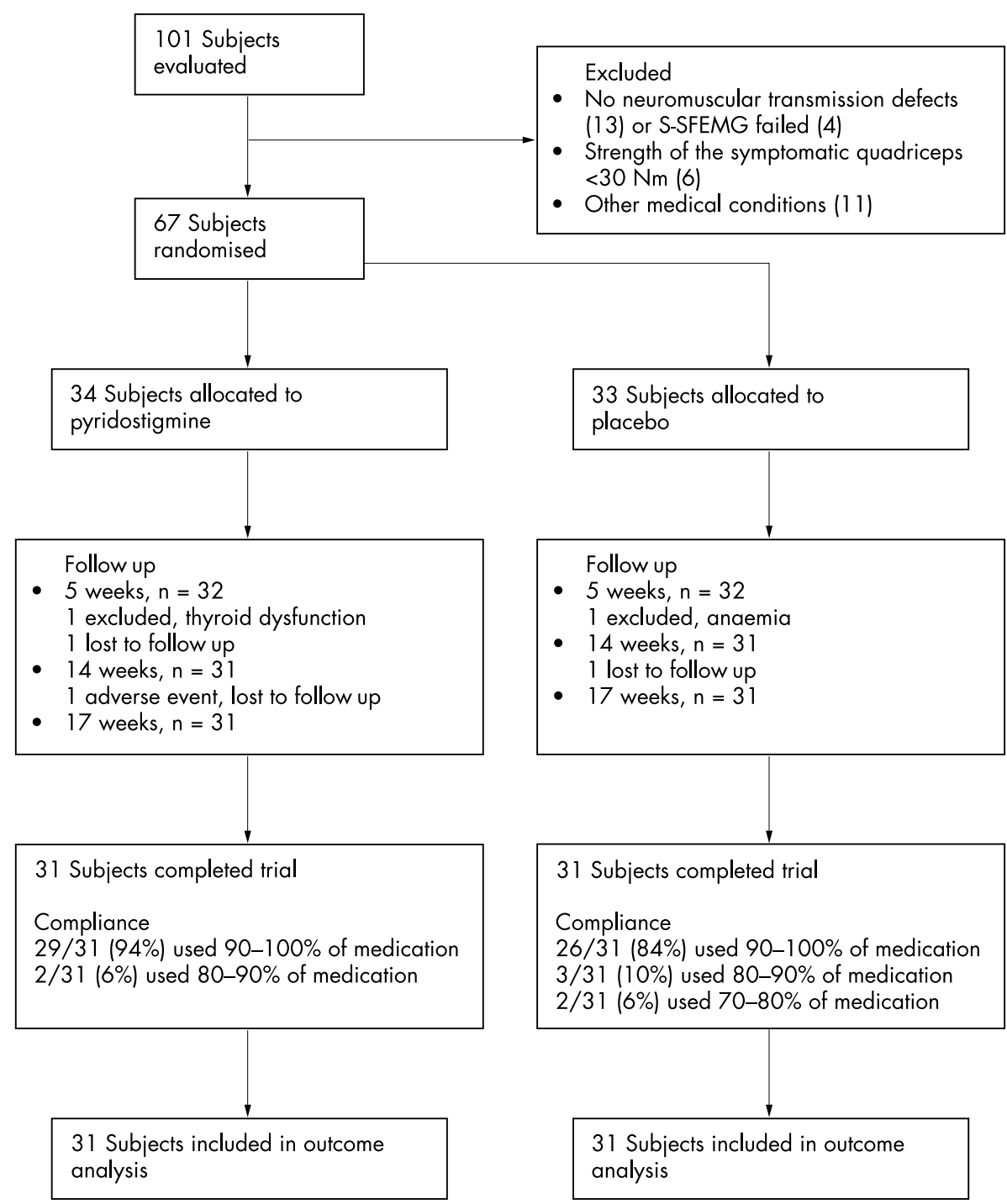

Figure 1 The number of subjects measured at the study visits during the trial and the compliance with the study drug in the two groups. 
Table 1 Baseline characteristics according to treatment group

\begin{tabular}{|c|c|c|c|}
\hline $\begin{array}{l}\text { Characteristics/ } \\
\text { outcome measures }\end{array}$ & $\begin{array}{l}\text { Pyridostigmine } \\
(n=33)\end{array}$ & $\begin{array}{l}\text { Placebo } \\
(n=32)\end{array}$ & p Value \\
\hline Age (years) & $51(8)$ & $52(8)$ & 0.61 \\
\hline $\operatorname{Sex}(M / F)$ & $10 / 23$ & $13 / 19$ & 0.38 \\
\hline Age at polio onset (years) & $3.4(4.3)$ & $2.5(2.5)$ & 0.31 \\
\hline $\begin{array}{l}\text { Duration of PPS symptoms } \\
\text { (years) } \\
\text { Severity of paresis of the }\end{array}$ & $10.0(5.9)$ & $10.7(6.3)$ & 0.64 \\
\hline legs (range $0-48$ ) & $24(5)$ & $22(6)$ & 0.14 \\
\hline $\begin{array}{l}\text { Motor unit size (mV·ms) } \\
\text { Shortened fatigure }\end{array}$ & $3.7(2.4) \uparrow$ & $3.9(2.5)^{\star *}$ & 0.75 \\
\hline $\begin{array}{l}\text { quesitionnaire (range } 4-28 \text { ) } \\
\text { Nottingham health profile, }\end{array}$ & $20(6)$ & $19(5)$ & 0.63 \\
\hline $\begin{array}{l}\text { category "Energy" } \\
\text { (range 0-100) } \\
\text { Fatigue severity scale }\end{array}$ & $47(34)$ & $47(36)$ & 0.95 \\
\hline $\begin{array}{l}\text { (range 1-7) } \\
\text { Two minute walking }\end{array}$ & $5.6(0.8)$ & $5.8(1.0)$ & 0.38 \\
\hline $\begin{array}{l}\text { distance, comfortable } \\
\text { speed (m) } \\
\text { Maximum walking }\end{array}$ & $122(21)$ & $117(27)$ & 0.37 \\
\hline $\begin{array}{l}\text { performance, } 75 \mathrm{~m}(\mathrm{~s}) \\
\text { Walking duration }\end{array}$ & $58(14)$ & $64(22)+\dagger$ & 0.22 \\
\hline $\begin{array}{l}\text { (percentage of total time) } \\
\text { Quadriceps strength }(\mathrm{Nm})\end{array}$ & $\begin{array}{l}6.5(2.9)^{*} \\
90(43)\end{array}$ & $\begin{array}{l}7.0(2.7) \dagger \\
82(48)\end{array}$ & $\begin{array}{l}0.70 \\
0.51\end{array}$ \\
\hline $\begin{array}{l}\text { Maximum voluntary } \\
\text { activation (range 0-100) } \\
\text { Muscle fatigability on } \\
\text { surface EMG }\end{array}$ & 70 (17)§ & $69(22) \ddagger$ & 0.94 \\
\hline $\begin{array}{l}\left(\mathrm{MF}_{0-5 \mathrm{~s}}-\mathrm{MF}_{25-30 \mathrm{~s}}\right) \\
\text { Neuromuscular }\end{array}$ & $1.3(2.2)$ & $2.3(3.0)^{* *}$ & 0.17 \\
\hline transmission, jiitter ( $\mu \mathrm{s})$ & $40(13)$ & $40(14)$ & 0.90 \\
\hline
\end{tabular}

Except for sex, values are presented as mean (SD). Differences between the two groups were tested by $t$ tests $\left(\chi^{2}\right.$ for sex).

${ }^{*} n=9 ;\left\lceil n=12 ; \ddagger n=23 ;\left\{n=28 ; \cdot n=29 ;{ }^{* *} n=30 ;+\lceil n=31\right.\right.$.

PPS, postpoliomyelitis syndrome.

last week of treatment, $58 \%$ of the subjects in the pyridostigmine group improved on both quadriceps strength and walking distance, whereas $13 \%$ of the subjects in this group did not improve on either of these outcome measures $\left(p<0.05, \chi^{2}\right.$ test). In the placebo group, $32 \%$ improved on both outcome measures, whereas $19 \%$ did not $(\mathrm{p}=1.00)$.

In 24 subjects ( 10 pyridostigmine, 14 placebo), MVA could not be measured owing to inability to stimulate the quadriceps to exert at least $25 \%$ of the MVC $(n=21)$ or because of intolerance of the measurement $(n=3)$. In the fifth week of treatment and three weeks after the treatment period, MVA had improved significantly more in the pyridostigmine group than in the placebo group.

Data on muscle fatigability were missing for seven subjects in both the pyridostigmine and the placebo groups owing to recording artefacts. Muscle fatigability did not change in either group.

Jitter values were missing for three subjects in the placebo group (intolerance in two, technical failure in one) in the last week of treatment. No difference in change in jitter was found between the two groups.

\section{Subgroup analyses}

Motor unit size was missing in four subjects (three pyridostigmine, one placebo) owing to technical failures.

Motor unit size was increased in 23 subjects (12 pyridostigmine, 11 placebo) and was normal in 35 subjects (16 pyridostigmine, 19 placebo). For the subjects with enlarged motor units, no difference in change between the two groups was found for any outcome measure. For the subjects with normal sized motor units, walking distance improved $9.5 \mathrm{~m}$ more $(8.4 \%$; $\mathrm{p}=0.002)$, and maximum walking performance $2.9 \mathrm{~s}$ more $(4.5 \% ; \mathrm{p}=0.03)$ in the pyridostigmine group than in the placebo group. No differences in effects were found for subgroups based on walking distance or quadriceps strength.

\section{DISCUSSION}

Our study provided no evidence of any benefit of pyridostigmine in reducing fatigue in patients with postpoliomyelitis syndrome with increased fatigue and neuromuscular transmission defects in a quadriceps muscle with new neuromuscular symptoms. The only significant difference in change between the two study groups in the 14th week of treatment was for walking distance, though the improvement of $6 \%$ was less than considered clinically relevant. The main question to be answered is whether pyridostigmine is indeed ineffective as a treatment for postpoliomyelitis syndrome, or whether the negative result reflects shortcomings of the study.

\section{Was the dose of pyridostigmine adequate?}

Taking into account the negative result of a randomised controlled trial with $180 \mathrm{mg}$ a day, ${ }^{19}$ we increased the dose of pyridostigmine to $240 \mathrm{mg}$. To assess whether this dose was pharmacologically effective, changes in neuromuscular transmission defects were monitored (S-SFEMG). The fact that no significant improvement in neuromuscular transmission was found in the pyridostigmine group might suggest that the dose of $240 \mathrm{mg}$ was not adequate. However, the large standard deviation of the difference in jitter found in the placebo group (table 2), probably caused by large variation in neuromuscular transmission defects between endplates, indicates that the reproducibility of jitter was poor. Thus jitter was not an appropriate measure to establish the effectiveness of the pyridostigmine dose.

Nonetheless, plasma concentrations of pyridostigmine can vary greatly between individuals, ${ }^{36}$ and the dose may have been insufficient for an unknown number of subjects. This implies that individual adjustment may be required to obtain an effective dose.

\section{Was the ability to detect an effect of pyridostigmine adequate?}

The sample size of the study population was calculated with an expected standard deviation of 30 in the change in $\mathrm{NHP}_{\mathrm{E}}$ score. ${ }^{4}$ The $\mathrm{NHP}_{\mathrm{E}}$ scores which were obtained were in agreement with this assumption and confirmed an adequate power calculation. However, the $\mathrm{NHP}_{\mathrm{E}}$ showed a substantial ceiling effect at baseline, where 15 subjects $(23 \%)$ had a score of 0 . In addition, the $\mathrm{NHP}_{\mathrm{E}}$ scores in the placebo group decreased significantly during the treatment period. To demonstrate a beneficial effect of pyridostigmine, the scores in the pyridostigmine group would have to decrease by more than $33 \%$, which was only found possible in 15 subjects.

Fatigue was also measured with the FSS, which has more response choices and showed no ceiling effect. As the FSS also failed to improve with pyridostigmine, the lack of effect on the $\mathrm{NHP}_{\mathrm{E}}$ cannot be attributed to an insufficient ability to detect change.

\section{Does pyridostigmine have an effect on muscle function?}

In this study, many comparisons were made and statistically tested. By chance, multiple testing can yield significant differences that do not reflect true differences and may produce misleading results. ${ }^{37}$ Some of the significant differences found-for instance, on maximum walking performance and MVA three weeks after treatment-may therefore be coincidental. However, if these differences had resulted from chance alone, they would have been equally distributed over the two treatment groups. The significant improvements in walking distance, the duration of walking, quadriceps strength, and MVA were all in favour of the pyridostigmine 


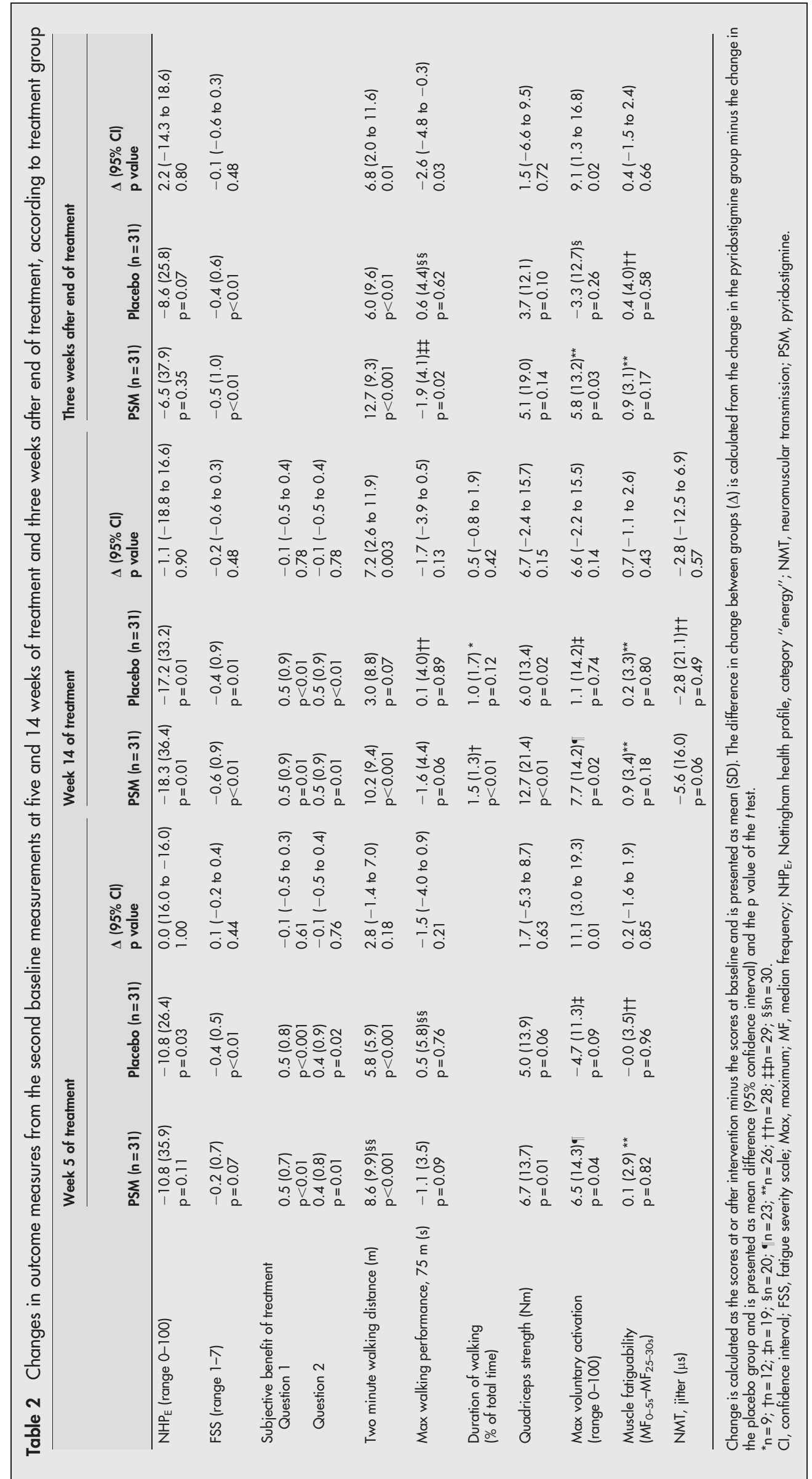


group. These findings suggest that pyridostigmine does improve muscle function to some extent. This is also supported by the significant association between the improvement in walking performance and the improvement in quadriceps strength, which was found in the pyridostigmine group but not in the placebo group.

It was expected that pyridostigmine would slow down muscle fatigability. However, no changes were found on the surface EMG during the treatment period in either of the two groups. The protocol used, with a sustained contraction at $40 \%$ of MVC (as obtained at baseline), did not induce high levels of fatigue, as was shown by the small decline in MF at baseline. This left little opportunity for improvement, and a relatively higher level of effort might have been more appropriate.

\section{Do subjects with normal sized motor units benefit more from pyridostigmine?}

It was hypothesised in advance that subjects with enlarged motor units would benefit most from pyridostigmine. ${ }^{915}$ Contrary to this expectation, subjects with normal sized motor units improved in walking performance, while those with enlarged motor units did not. Although this unexpected subgroup effect must be interpreted with caution, it should be realised that all quadriceps muscles were symptomatic, and all showed abnormal neuromuscular transmission. An explanation might be that the normal sized motor units were, in fact, enlarged motor units that had become reduced in size over time owing to the distal degeneration of axonal branches. ${ }^{12} 3839$

\section{Conclusions}

The result of this trial was negative, as pyridostigmine did not reduce fatigue in a selected group of subjects with postpoliomyelitis syndrome who were most likely to benefit from this treatment. On the other hand, the significant effect of pyridostigmine on walking distance-together with some effects on walking duration, quadriceps strength, and maximum voluntary activation-suggest that pyridostigmine may improve muscle function. The effect of pyridostigmine might be related to the size of the motor units with neuromuscular transmission defects. In subjects with normal sized motor units, the effect size might be of relevance. However, a confirmatory study is needed as this finding resulted from a subgroup analysis that was not prespecified.

Because no effect was found on perceived fatigue, future studies should concentrate on the effects of individually adjusted doses of pyridostigmine on physical performance in subjects with postpoliomyelitis syndrome.

\section{ACKNOWLEDGEMENTS}

The study was supported by a grant No MAR98-0112 from the Prinses Beatrix Fonds, Netherlands. Pyridostigmine was provided by ICN Pharmaceuticals Inc, Zoetermeer, Netherlands. Placebo pyridostigmine was manufactured by Medisch Centrum Haaglanden, The Hague, Netherlands. Placebo atropine was manufactured by the Pharmacy Department of the VU University Medical Centre, Amsterdam, Netherlands.

\section{Authors' affiliations}

H L D Horemans, F Nollet, A Beelen, G J Lankhorst, Department of Rehabilitation Medicine, VU University Medical Centre, Amsterdam, Netherlands

G Drost, D F Stegeman, M J Zwarts, Department of Clinical Neurophysiology, University Medical Centre Nijmegen, Netherlands J B J Bussmann, Department of Rehabilitation Medicine, Erasmus MC, University Medical Centre Rotterdam, Netherlands

M de Visser, Department of Neurology, Academic Medical Centre, University of Amsterdam, Netherlands

Competing interests: none declared

\section{REFERENCES}

1 Halstead LS. Post-polio syndrome: definition of an elusive concept. In: Munsat TL, editor. Post-polio syndrome. Stoneham, MA: ButterworthHeinemann, 1991:23-38.

2 Jubelt B, Cashman NR. Neurological manifestations of the post-polio syndrome. Crit Rev Neurobiol 1987;3:199-220.

3 Halstead LS, Rossi CD. New problems in old polio patients: results of a survey of 539 polio survivors. Orthopedics 1985;8:845-50.

4 Nollet $F$, Beelen A, Prins $M H$, et al. Disability and functional assessment in former polio patients with and without postpolio syndrome. Arch Phys Med Rehabil 1999;80:136-43.

5 Berlly MH, Strauser WW, Hall KM. Fatigue in postpolio syndrome. Arch Phys Med Rehabil 1991;72:115-18.

6 Packer TL, Martins I, Krefting L, et al. Activity and post-polio fatigue. Orthopedics 1991;14:1223-6.

7 Packer TL, Sauriol A, Brouwer B. Fatigue secondary to chronic illness: postpolio syndrome, chronic fatigue syndrome, and multiple sclerosis. Arch Phys Med Rehabil 1994;75:1122-6.

8 Trojan DA, Gendron D, Cashman NR. Anticholinesterase-responsive neuromuscular junction transmission defects in post-poliomyelitis fatigue. J Neurol Sci 1993; 114:170-7.

9 Cashman NR, Maselli R, Wollmann RL, et al. Late denervation in patients with antecedent paralytic poliomyelitis. N Engl J Med 1987;317:7-12.

10 Ravits J, Hallett M, Baker M, et al. Clinical and electromyographic studies of postpoliomyelitis muscular atrophy. Muscle Nerve 1990;13:667-74.

11 Wiechers DO. New concepts of the reinnervated motor unit revealed by vaccine-associated poliomyelitis. Muscle Nerve 1988;11:356-64.

12 Wiechers DO, Hubbell SL. Late changes in the motor unit after acute poliomyelitis. Muscle Nerve 1981;4:524-8.

13 Cashman NR, Trojan DA. Correlation of electrophysiology with pathology, pathogenesis, and anticholinesterase therapy in post-polio syndrome. Ann NY Acad Sci 1995;753:138-50.

14 Dalakas MC. Pathogenetic mechanisms of post-polio syndrome: morphological, electrophysiological, virological, and immunological correlations. Ann NY Acad Sci 1995:753:167-85.

15 Maselli RA, Cashman NR, Wollman RL, et al. Neuromuscular transmission as a function of motor unit size in patients with prior poliomyelitis. Muscle Nerve 1992; 15:648-55.

16 Allen GM, Gandevia SC, Neering IR, et al. Muscle performance, voluntary activation and perceived effort in normal subjects and patients with prior poliomyelitis. Brain 1994;117:661-70.

17 Girlanda P, Nicolosi C, Venuto C, et al. Pyridostigmine treatment of post-polio syndrome fatigue: a single fibre EMG study. Eur J Neurol 1996;3:130-5

18 Trojan DA, Cashman NR. An open trial of pyridostigmine in post-poliomyelitis syndrome. Can J Neurol Sci 1995;22:223-7.

19 Trojan DA, Collet JP, Shapiro S, et al. A multicenter, randomized, doubleblinded trial of pyridostigmine in postpolio syndrome. Neurology 1999;53:1225-33.

20 Nollet $F$, Horemans $H$, Beelen A. A multicenter, randomized, double-blinded trial of pyridostigmine in postpolio syndrome [letter]. Neurology 2000;55:899-901.

21 Freeman JA, Hobart JC, Langdon DW, et al. Clinical appropriateness: a key factor in outcome measure selection: the 36 item short form health survey in multiple sclerosis. J Neurol Neurosurg Psychiatry 2000;68:150-6.

22 Shields RK, Ruhland JL, Ross MA, et al. Analysis of health-related quality of life and muscle impairment in individuals with amyotrophic lateral sclerosis using the medical outcome survey and the Tufts Quantitative Neuromuscular Exam. Arch Phys Med Rehabil 1998;79:855-62.

23 Alberts $M$, Smets EM, Vercoulen JH, et al. Abbreviated fatigue questionnaire: a practical tool in the classification of fatigue. Ned Tijdschr Geneeskd 1997;141:1526-30, [In Dutch].

24 Borg K. Post-polio muscle dysfunction. Neuromuscul Disord 1996;6:75-80.

25 Tronteli JV, Mihelin M, Fernandez JM, et al. Axonal stimulation for end-plate jitter studies. J Neurol Neurosurg Psychiatry 1986;49:677-85.

26 Gilchrist JM. Single fiber EMG reference values: a collaborative effort. Ad Hoc Committee of the AAEM Special Interest Group on Single Fiber EMG. Muscle Nerve 1992;15:151-61.

27 Medical Research Council. Aids to the examination of the peripheral nervous system. London: HMSO, 1976.

28 van Alphen $\mathrm{E}$, Blok JH, Vingerhoets $\mathrm{HM}$, et al. Estimation from surface EMG of the distribution of motor unit sizes in the $\mathrm{m}$ vastus lateralis. World Congress on Medical Physics and Biomedical Engineering, Chicago (USA), July 23-28, 2000. Electronic citation: www.vumc.nl

29 Erdman RA, Passchier J, Kooijman M, et al. The Dutch version of the Nottingham Health Profile: investigations of psychometric aspects. Psychol Rep 1993;72:1027-35

30 Krupp LB, LaRocca NG, Muir-Nash J, et al. The fatigue severity scale. Application to patients with multiple sclerosis and systemic lupus erythematosus. Arch Neurol 1989:46:1121-3.

31 Guy W. ECDEU assessment manual for psychopharmacology. Rockville, MD: National Institute of Mental Health, 1976:218-22.

32 Bussmann JB, Martens WL, Tulen JH, et al. Measuring daily behavior using ambulatory accelerometry: the Activity Monitor. Behav Res Methods Instrum Comput $2001 ; 33: 349-56$

33 Rodriquez AA, Agre JC. Electrophysiologic study of the quadriceps muscles during fatiguing exercise and recovery: a comparison of symptomatic and asymptomatic postpolio patients and controls. Arch Phys Med Rehabil 1991;72:993-7. 
34 Tronteli JV, Stalberg E. Jitter measurement by axonal micro-stimulation. Guidelines and technical notes. Electroencephalogr Clin Neurophysiol 1992;85:30-7.

35 Stalberg E, Trontelj J. Single fiber electromyography. Studies in healthy and diseased muscle. New York: Raven Press, 1994.

36 Breyer-Pfaff U, Schmezer A, Maier U, et al. Neuromuscular function and plasma drug levels in pyridostigmine treatment of myasthenia gravis. J Neurol Neurosurg Psychiatry 1990;53:502-6.
37 Altman DG. Clinical trials. In: Practical statistics for medical research. Boca Raton, FL: Chapman Hall/CRC Press, 1999.

38 Grimby G, Stalberg E, Sandberg A, et al. An 8-year longitudinal study of muscle strength, muscle fiber size, and dynamic electromyogram in individuals with late polio. Muscle Nerve 1998;21:1428-37.

39 Tam SL, Archibald V, Tyreman N, et al. Effect of exercise on stability of chronically enlarged motor units. Muscle Nerve 2002;25:359-69.

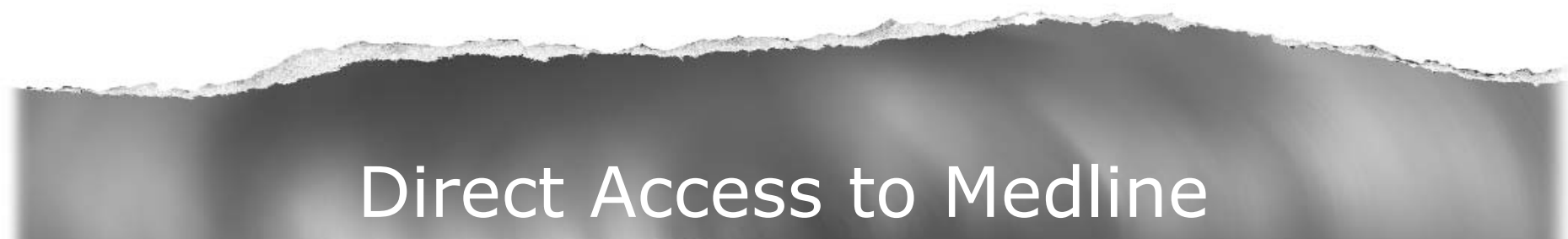

\section{Medline}

Link to Medline from the homepage and get straight into the National Library of Medicine's premier bibliographic database. Medline allows you to search across 9 million records of bibliographic citations and author abstracts from approximately 3,900 current biomedical journals.

www.jnnp.com 